
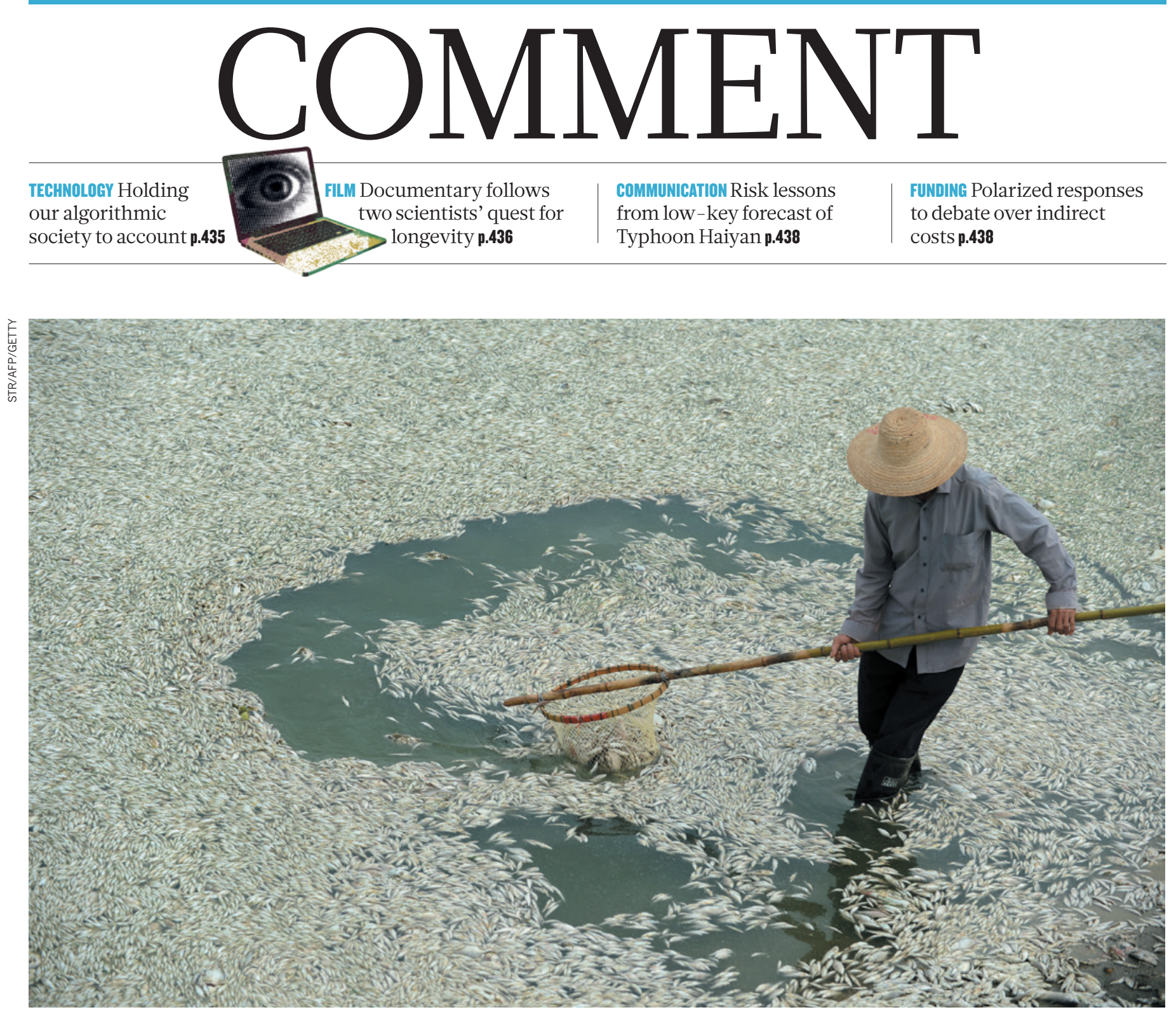

A resident of China's Hubei province clears the Fuhe river of dead fish, thought to have been poisoned by high levels of ammonia.

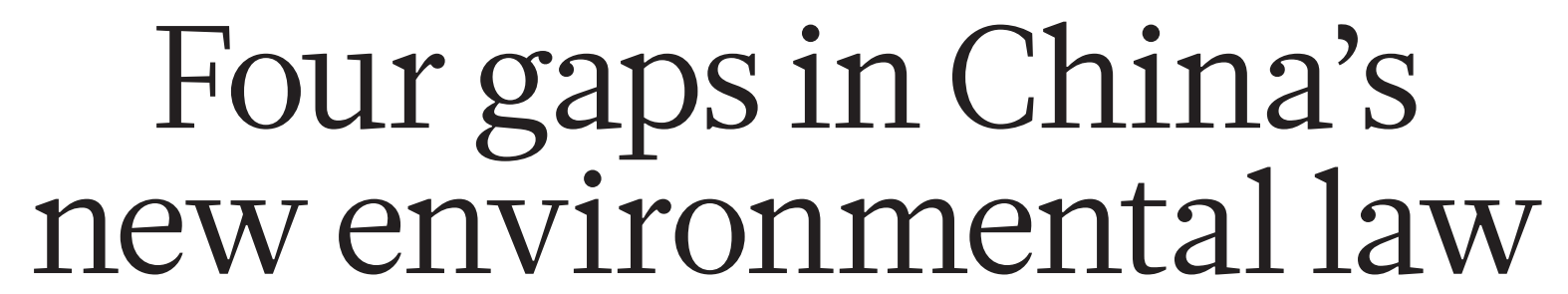
Implementation and accountability will remain challenging, especially at the local level, warn Bo Zhang and Cong Cao.

$\mathrm{O}$ n 1 January, a new environmental protection law (EPL) took effect in China. It is the nation's first attempt to harmonize economic and social development with environmental protection.

The EPL is perceived as the most progressive and stringent law in the history of environmental protection in China. It details harsher penalties for environmental offences - for example, for acts of tampering and falsifying data, discharging pollutants covertly and evading supervision. It contains provisions for tackling pollution, raising public awareness and protecting whistle-blowers. It places more responsibility and accountability on local governments and law-enforcement agencies and sets higher standards for enterprises. Yet the law is not enough. For the following reasons it will face many challenges ${ }^{1}$.

\section{FOUR GAPS}

First, the power of the new law is limited. The EPL can be trumped by other legislation such as the specific agriculture, forestry, grassland and water laws, which 


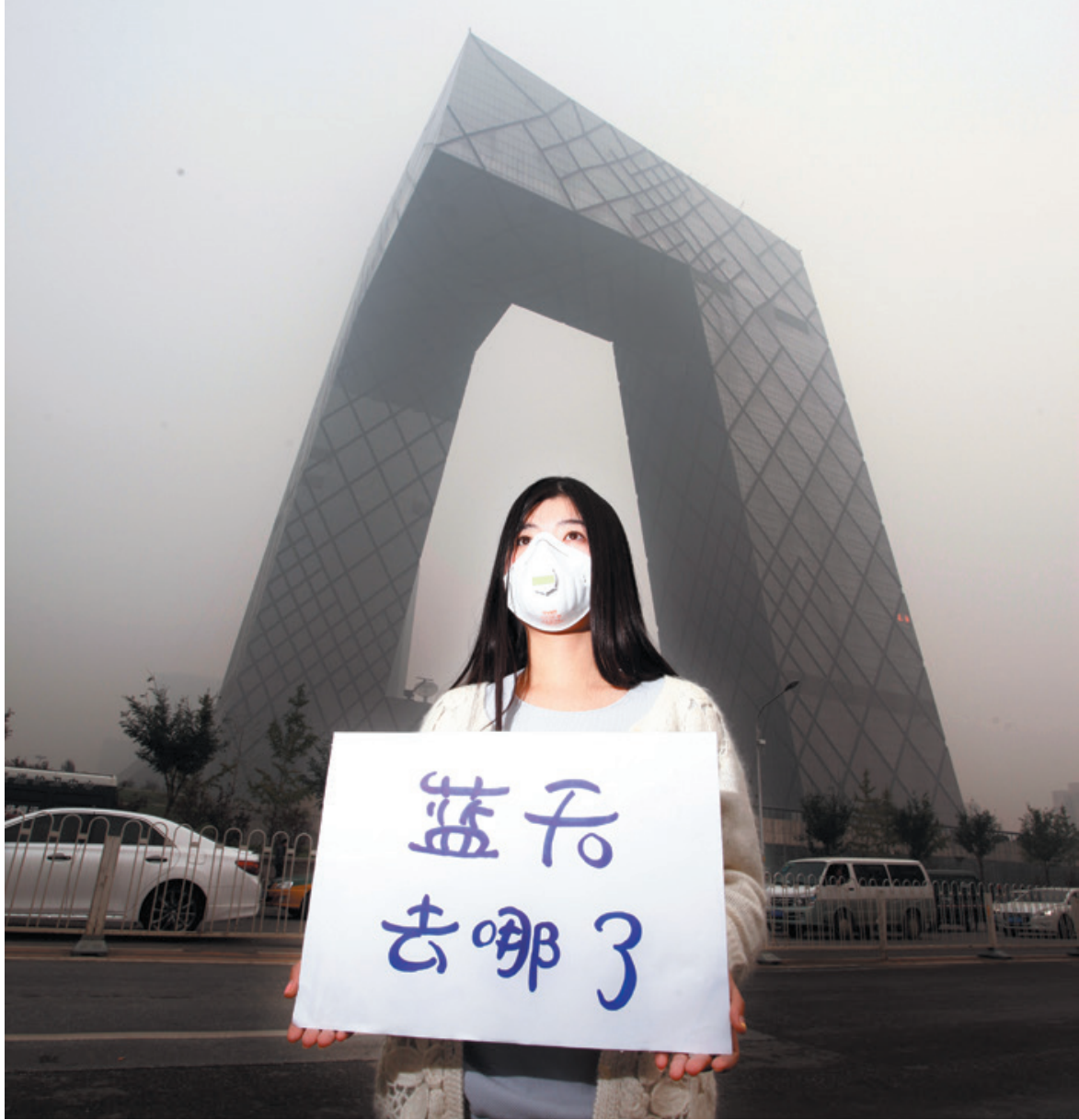

‘Where has the blue sky gone?' asks a citizen in Beijing during a period of heavy smog in 2014.

- are aimed at protecting these resources. Consequently, the departments responsible for managing these natural resources could challenge EPL provisions.

Many countries have enacted basic environmental-protection legislation to avoid this situation. For example, in 1969, the United States formulated the National Environmental Policy Act, which placed legal obligations and liabilities for environmental protection on all federal agencies ${ }^{2}$. In 1993, Japan replaced its Basic Law for Environmental Pollution and its Natural Environment Preservation Law with a comprehensive Basic Environment Law ${ }^{3}$.

Second, enforcement of the EPL will be hampered by the fragmented and overlapping structure of environmental governance in China. At present, the environment and natural resources are overseen by several agencies, including the Ministry of Environmental Protection, the ministries of water resources, land and resources, and agriculture, the State Oceanic Administration and the State Forestry Administration ${ }^{4}$. China's carbon-tax and emissions-trading systems, overseen by the National Development and Reform Commission, are not included in the law.

Other countries practise independent and unified environmental supervision. In the United States, the Council on Environmental Quality, which reports to the president, coordinates federal agencies and implements environmental policies at the federal, state and local government level. Meanwhile, the

Environmental Protection Agency is responsible for overall environmental governance representing the federal government and working through independent law enforcement $^{3}$. Italy's Ministry of the Environment, Land and Sea takes overall responsibility for protecting the country's land, ocean, rivers, wetlands and forests. Other examples include Germany's Federal Ministry for the Environment, Nature Conservation, Building and Nuclear Safety, and Brazil's Ministry of the Environment.

Third, despite increasingly damaging pollution in China, the new EPL fails to acknowledge citizens' basic right to an environment fit for life. So far, 149 devel-

\section{"The new}

law fails to acknowledge citizens' basic right to an environment fit for life." new law clearly gives citizens, civic groups and non-governmental organizations (NGOs) the right to obtain environmental information and to participate in environmental governance, these parties (with the exception of NGOs that fulfil certain criteria) are not allowed to bring lawsuits against the government if there are, for example, serious lapses in air or water quality. A public environmental litigation system is needed to provide cost-effective redress for those affected.

Fourth, enforcement and implementation of the law may be foiled by a lack of capacity and by conflicts of interest. Environmental governance in China is mainly exercised locally by environmental protection bureaus. The environment ministry primarily provides guidance to these bodies, but does not have sufficient authority over them. Local governments (which are often more interested in economic growth) keep a firm grip on the staffing and financing of the environmental protection bureaus and hence on their decision-making ${ }^{4}$. This means that, in effect, the protection bureaus do not have the power to impose severe penalties on companies or individuals in breach of environmental statute, nor do the bureaus face legal or other consequences of failure to do so.

\section{PLUGGING THE GAPS}

In October 2014, the Central Committee of the Communist Party of China decided to establish a recording, communication and accountability system. This is intended to limit judicial intervention by government officials, and to integrate promoting the rule of law into the remit of officials at all levels. The system could restrain officials, and indeed the party itself, from advising judges on how to decide on court cases, including those pertaining to the EPL.

Fundamentally, as Alex Wang, an environmental law specialist at the University of California, Los Angeles, has written, environmental protection in China needs to be raised to "a level of priority previously reserved only for the most important partystate mandates, such as economic growth, social stability, and the one-child policy"6.

Effective environmental governance needed a new law. Now it requires robust implementation mechanisms, accountability regimes and institutional arrangements.

Bo Zhang is a research fellow at the Information Center, Ministry of

Environmental Protection, China.

Cong Cao is associate professor and reader at the School of Contemporary Chinese Studies, University of Nottingham, UK. e-mails:zhangbo@mep.gov.cn; cong.cao@nottingham.ac.uk

1. McElwee, C. R. Environmental Law in China: Mitigating Risk and Ensuring Compliance (Oxford Univ. Press, 2011).

2. Hahn, R. W. Nat. Resour. J. 34, 305-348 (1994).

3. Ren, Y. Int. Rev. Environ. Strategies 1, 79-96 (2000).

4. Economy, E. C. The River Runs Black: The Environmental Challenge to China's Future 2nd edn (Cornell Univ. Press, 2010).

5. Boyd, D. R. The Status of Constitutional Protection for the Environment in Other Nations (David Suzuki Foundation, 2014).

6. Wang, A. L. Harvard Environ. Law Rev. 37, 365-440 (2013).

The views expressed are those of the authors and do not necessarily reflect the official view of China's Ministry of Environmental Protection. 